AperTO - Archivio Istituzionale Open Access dell'Università di Torino

\title{
Comment on helicobacter pylori eradication using metronidazole
}

\section{This is the author's manuscript}

Original Citation:

\section{Availability:}

This version is available http://hdl.handle.net/2318/1717393

since 2019-11-24T16:39:29Z

Terms of use:

Open Access

Anyone can freely access the full text of works made available as "Open Access". Works made available under a Creative Commons license can be used according to the terms and conditions of said license. Use of all other works requires consent of the right holder (author or publisher) if not exempted from copyright protection by the applicable law. 


\title{
Comment on Helicobacter pylori eradication using metronidazole
}

\author{
Ramy Younes ${ }^{1}$, Anna Morgando ${ }^{1}$ \\ ${ }^{1}$ University of Torino, Department of Medical Sciences, Gastroenterology Unit, Torino, Italy
}

Corresponding Author

Ramy Younes

University of Torino

Department of Medical Sciences

Gastroenterology Unit, Torino, Italy

011.6335569

ibrahim.massimo@gmail.com

Key words: Helicobacter pylori, therapy, metronidazole

Short title: Helicobacter pylori treatment 
The recent open-label, single-arm study, published by Marušic et al. has arisen a great interest. ${ }^{1}$ In fact, in the same issue both an editorial ${ }^{2}$ and a comment letter ${ }^{3}$ have been published. At the end of the latter the authors reported that "also, the application of metronidazole in therapeutic regimens should be confirmed following susceptibility tests since a relatively high rate of antibiotic resistance is globally reported”. ${ }^{3}$ Although several clinical trials comparing tailored treatment versus empiric treatment, have reported a satisfactory eradication rate with the former and not with the latter strategy, we would highlight that in some contexts there is no need to perform endoscopy and/or culture test is not available, therefore the possibility to have an empiric strategy of proved efficacy is of main importance. The choice of the more appropriate treatment should be based on local antibiotic usage, documented antibiotic resistance and outcome data. Focusing on metronidazole resistance, although highly prevalent, can be partly overcome and is of secondary importance. ${ }^{4}$ Hence, the need to evaluate metronidazole resistance patient by patient, could not be useful. It would be better to know in a specific population the metronidazole resistance rates (since population results are not transferable to other geographical areas with different pattern of resistance), and apply the recommendation of the more updated Guidelines. $^{5}$

\section{References}

1. Marušic M, Dominkovic L, Majstorovic Barac K, Gulic S, Bago J, Pezerovic D. Bismuthbased quadruple therapy modified with moxifloxacin for Helicobacter pylori eradication. Minerva Gastroenterol Dietol 2017;63:80-4.

2. Graham DY, Fagoonee S, Pellicano R. Increasing role for modified bismuth-containing quadruple therapies for Helicobacter pylori eradication. Minerva Gastroenterol Dietol 2017;63:77-9.

3. Talebi Bezmin Abadi A, Shafahi Tilaki S, Fattahi G, Safarnejad S. Moxifloxacin but not metronidazole can be used in therapeutic regimens against Helicobacter pylori. Minerva Gastroenterol Dietol 2017;63:167. 
4. Pellicano R, Ribaldone DG, Fagoonee S, Astegiano M, Saracco G, Mégraud F. A 2016 panorama of Helicobacter pylori infection: key messages for clinicians. Panminerva Med 2016;58:304-17.

5. Malfertheiner P, Mégraud F, O'Morain CA, Gisbert JP, Kuipers EJ, Axon AT, et al. Management of Helicobacter pylori infection - The Maastricht V/Florence Consensus Report. Gut 2017;66:6-30. 